\title{
Switch antenna array capable of high gain coverage in half space
}

\author{
Tao Dang ${ }^{1}$, Yin Tian $^{2}$, Guang-ming Wang ${ }^{1}$, and Jun Ouyang ${ }^{3 a)}$ \\ ${ }^{1}$ Missile Institute of Air Force Engineering University, \\ 1 Jia, East Changle Road, Xi'an, Shanxi 710051, China \\ 2 Sichuan Jiuzhou Electric Group Co. Ltd., \\ 257 Jiuzhou Road, ChuangYuan Zone, Mianyang, Sichuan 621000, China \\ ${ }^{3}$ University of Electronic Science and Technology of China, \\ 2006 XiYuan Road, Hi-tech Zone, Chengdu, Sichuan 611731, China \\ a)yjou@uestc.edu.cn
}

\begin{abstract}
In this paper, a switching satellite antenna array capable of realizing high gain coverage in half space is designed, and a multi-antenna system conforming to the structure of the pedestal is combined with a feed based on RF switch. In the feed network, 19 beams were designed for spatial coverage, so that an antenna pattern of right-hand circular polarization gain of not less than $8 \mathrm{~dB}$ within azimuth angle $0-360^{\circ}$ and pitch angle $0-70^{\circ}$ was achieved. The area ratio of circular polarization is less than $3 \mathrm{~dB}$. The test results are in good agreement with the simulation results.
\end{abstract}

Keywords: switch antenna, high gain coverage

Classification: Microwave and millimeter-wave devices, circuits, and modules

\section{References}

[1] W. K. Lo, et al.: "L-shaped probe-feed circularly polarized microstrip patch antenna with a cross slot," Microw. Opt. Technol. Lett. 25 (2000) 251 (DOI: 10.1002/(SICI)1098-2760(20000520)25:4<251::AID-MOP7>3.0.CO;2-H).

[2] Nasimuddin, et al.: "Wideband circularly polarized stacked microstrip antenna," IEEE Antennas Wireless Propag. Lett. 6 (2007) 21 (DOI: 10.1109/ LAWP.2006.890749).

[3] Z. Wang, et al.: "Single-fed broadband circularly polarized stacked patch antenna with horizontally meandered strip for universal UHF RFID applications," IEEE Trans. Microw. Theory Techn. 59 (2011) 1066 (DOI: 10. 1109/TMTT.2011.2114010).

[4] C. Deng, et al.: "A wideband sequentialphase fed circularly polarized patch array," IEEE Trans. Antennas Propag. 62 (2014) 3890 (DOI: 10.1109/TAP. 2014.2321380).

[5] Q. Liu, et al.: "Compact ultrawideband circularly polarized weakly coupled patch array antenna," IEEE Trans. Antennas Propag. 65 (2017) 2129 (DOI: 10. 1109/TAP.2017.2671455).

[6] C. Li, et al.: "A dual-band circularly polarized antenna with wide HPBWs for CNSS applications," IEICE Electron. Express 15 (2018) 20180409 (DOI: 10. 1587/elex.15.20180409). 
[7] J. Lin, et al.: "AMC-based planar antenna with low-profile and broad CP beamwidth," IEICE Electron. Express 14 (2017) 20170473 (DOI: 10.1587/ elex.14.20170473).

[8] C. Wu, et al:: "Broad beamwidth circular polarization antenna: Microstripmonopole antenna," IET Electron. Lett. 48 (2012) 1176 (DOI: 10.1049/ el.2012.1559).

[9] C. D. McCarrick: "Mechanically-steered disk antenna for mobile satellite service," International Mobile Satellite Conference (1995) 345.

[10] K. Feng, et al.: "A phased array antenna system for INMARSAT mobile ground terminal," Propagation and EMC Technologies for Wireless Communications (2009) 415 (DOI: 10.1109/MAPE.2009.5355525).

[11] M. Geissler, et al.: "Design and test of an L-band phased array for maritime satcom antennas and propagation," Proc. of the 5th European Conference (2011) 2871.

[12] T. Blersch, et al.: "A switched beam antenna for hemispherical coverage," International ITG Workshop, Conference Publications (2012) 181 (DOI: 10. 1109/WSA.2012.6181203).

\section{Introduction}

At present, the maritime satellite system has been widely used, and the development of terminal antenna has also received more attention. The demand for array antennas with high gain coverage, circular polarization, small size, and low-profile is increasing. In [1], the L-shaped probe is used for feeding, and the overlap bandwidth of the $-10 \mathrm{~dB}$ impedance bandwidth and the $3 \mathrm{~dB}$ axial ratio bandwidth is about $14 \%$. In [2] adopts the form of laminated microstrips. The foam material is added between the upper and lower substrates to increase the bandwidth. The $-10 \mathrm{~dB}$ impedance bandwidth is $21 \%$, and the $3 \mathrm{~dB}$ axial ratio bandwidth is $13.5 \%$. In [3] uses a combination of a sigma-shaped transmission line feed and a stacked parasitic patch. The $-10 \mathrm{~dB}$ impedance bandwidth is about $25.8 \%$, and the $3 \mathrm{~dB}$ axis ratio bandwidth is $13.5 \%$. In [4], the arc microstrip is fed by the probe, so that only a single-layer plate structure is needed, and a circularly polarized radiation mode with similar frequency is excited for the ring structure excitation, and the 3$\mathrm{dB}$ axial ratio bandwidth is $12.7 \%$. In [5], by introducing a weak coupling mechanism into the feed structure, the impedance bandwidth reaches $98 \%$, and the $3 \mathrm{~dB}$ axis ratio bandwidth reaches $96.8 \%$. A dual-band circularly polarized (CP) antenna with wide half power beamwidth (HPBWs) of over $122^{\circ}$ for compass navigation satellite system (CNSS) applications is proposed in [6]. In [7], AMCbased planar antenna accomplishes a wide $3-\mathrm{dB}$ AR beamwidth $\left(>135^{\circ}\right)$ and exhibits a low-profile property with the height of $0.054 \lambda 0$, which can be applied in the BeiDou Satellite System (BDS). In [8], Microstrip antenna loading with monopoles around is proposed to widen the $3-\mathrm{dB}$ AR beamwidth.

In maritime satellite communication applications, depending on the way of tracking satellites, it can be divided into mechanical scanning tracking and electrical scanning tracking. In early applications, people mainly used mechanical scanning to achieve coverage of the wide-angle area of the antenna. In [9], a microstrip antenna array is used as the radiating element, a wide beam is formed on 
the elevation plane, and a narrow beam is formed on the azimuth plane. The minimum gain is $9 \mathrm{dBi}$ in the range of the elevation angle of $25^{\circ} \sim 60^{\circ}$, and the axial ratio is $4.5 \mathrm{~dB}$. Between $\sim 5.7 \mathrm{~dB}$, the antenna is mechanically rotated to achieve gain coverage in the range of $0 \sim 360^{\circ}$ of the azimuth plane. In [10], a planar phased array antenna is designed to achieve spatial area gain coverage. The antenna unit uses a dual-frequency microstrip antenna to cover the transceiving frequency bands of maritime satellite communications. Circular polarized radiation is achieved by square slots on the edge of the patch, a total of 19 Units, each unit followed by a T/R module, can independently adjust the amplitude and phase. Through phase scanning, the antenna can achieve a gain coverage of at least $14 \mathrm{~dB}$ in the range of elevation angle of $30^{\circ} \sim 90^{\circ}$ and azimuth angle of $0 \sim 360^{\circ}$. The axial ratio in the coverage area is less than $5.8 \mathrm{~dB}$ and the overall size is $550 \mathrm{~mm} 550 \mathrm{~mm} 110 \mathrm{~mm}$. In [11], a 26-cell stereo structure phased array antenna was designed. The antenna unit uses a single-point fed microstrip circularly polarized antenna. The antenna carrier layout structure is similar to a football shape, and each unit is located on a polygonal surface of the carrier, each subsequent $T / R$ component independently adjusts the amplitude phase, and finally achieves a coverage of $-15^{\circ} \sim 90^{\circ}$ at an elevation angle, a gain greater than $12.8 \mathrm{~dB}$ in an azimuth angle of $0 \sim 360^{\circ}$, and an axial ratio less than $3 \mathrm{~dB}$. In [12], an array antenna with fixed beam switching is designed. The high elevation angle region is covered by three elements in the upper layer to form three beams, and the low elevation angle region is radiated by the lower 6 units and the two adjacent units are simultaneously Working with a total of 12 beams to cover, a total of 15 beams, the coverage gain in the upper half of the space is $7.5 \mathrm{dBi}$.

Since the fixed beam switching form array antenna has high stability and fasttracking speed compared to the mechanical scanning array, it is less expensive to manufacture compared to the phased array antenna and is suitable for commercial applications. Therefore, this paper focuses on using as few antenna elements as possible. The simplest structure allows for high gain coverage and good circular polarization performance. Through the multi-antenna system conformal to the pedestal structure combined with the feed network based on RF switch, 19 beams were designed for spatial coverage, so that the azimuth angle of $0 \sim 360^{\circ}$ and the elevation angle of $0 \sim 70^{\circ}$ were not within the spatial range. Less than $8 \mathrm{~dB}$ righthand circular polarization gain antenna pattern, and the circular polarization axis ratio is less than $3 \mathrm{~dB}$ in the full-angle domain.

By processing the corresponding hardware, the test results are in good agreement with the simulation results, which further validates the feasibility of the design.

\section{Antenna elements}

The antenna unit model is shown in Fig. 1. The dielectric substrate material is Rogers R04350, the sheet thickness is $0.8 \mathrm{~mm}$, and the dielectric constant is 3.66. The antenna unit adopts a square patch form. In order to meet the bandwidth requirement, a parasitic patch is added at a certain height above the lower main patch. And the air is used as the dielectric substrate. In actual production, a copper 
piece of corresponding size can be attached to the lower surface of the radome as a parasitic patch. The radome is made of ABS engineering plastic with a dielectric of 3.1 and a thickness of $2.3 \mathrm{~mm}$.

In order to make the antenna unit have better circular polarization characteristics, a double-point orthogonal feeding method is adopted for the lower main patch, and two orthogonal polarization directions are excited in the $\mathrm{X}$-axis and Y-axis directions, making the $\mathrm{X}$-axis direction excitation phase ahead of the Y-axis direction by $90^{\circ}$, forming right-hand circularly polarized radiation.

As shown in Fig. 1(a)(b), the length of the main patch side of the antenna unit is named L_DP, and the side length of the parasitic patch is named L_PP. The height of the air layer between them is named h_air. These three parameters have the greatest impact on the operating frequency band of the antenna. L_DP and L_PP determine their respective resonant frequency points. h_air determines whether the parasitic patch can be excited at the desired frequency and the effect of the parasitic patch on the impedance of the main patch port.

The feed network uses a $3 \mathrm{~dB}$ branch line coupler in the form of a microstrip, which is printed on the underlying dielectric board along with the underlying main patch. The overall structure of the antenna combined with the antenna unit and the feed network is shown in Fig. 2. The overall size of the antenna is $135 \mathrm{~mm} *$ $135 \mathrm{~mm} * 12.8 \mathrm{~mm}$. Fig. 3(a) shows the simulation results of the antenna unit return loss, Fig. 3(b) shows the unit normal point gain and the axial ratio sweep curve, and Fig. 4 shows the center frequency point main plane. Fig. 5 is the simulation result of the center frequency point axis ratio.

The simulation results show that the return loss of the antenna element is less than $-10 \mathrm{~dB}$ in the frequency band of $1.4 \mathrm{GHz}$ to $1.78 \mathrm{GHz}$. The radiation direction is normal, and there is no wave beam offset phenomenon. The maximum gain is at 1.64 GHz. The normal gain is higher than $8.2 \mathrm{~dB}$. And the axial ratio is less than $3 \mathrm{~dB}$ in the frequency band of $1.52 \mathrm{GHz}$ to $1.66 \mathrm{GHz}$. The $3-\mathrm{dB}$ beam width of the center frequency is 65 degrees. The gain is more than $8 \mathrm{~dB}$ when Theta in the angle between positive and negative 13.5 degrees, and the axial ratio is less than $3 \mathrm{~dB}$ when Theta in the angle between positive and negative 45 degrees.

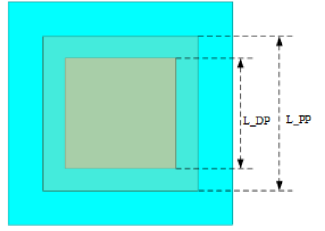

(a)

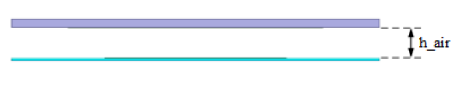

(b)

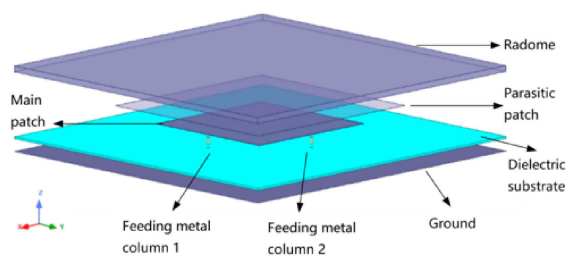

(c) 


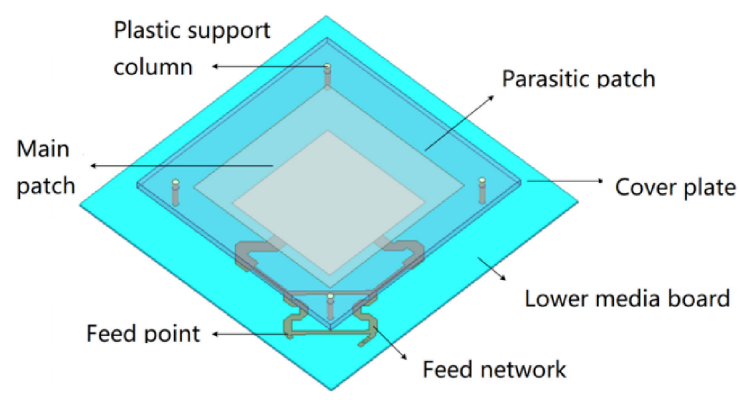

(a)

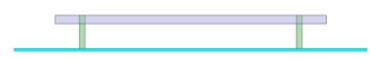

(b)

Fig. 2. Antenna element structure diagram. (a) Antenna element overall schematic; (b) Antenna element side view

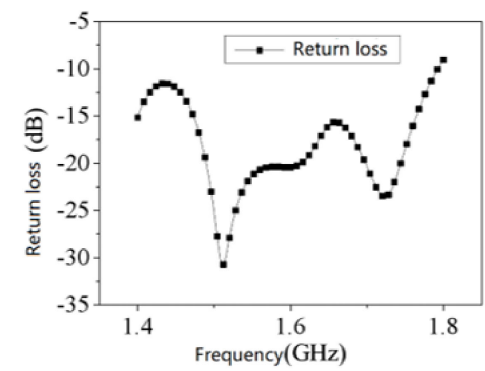

(a)

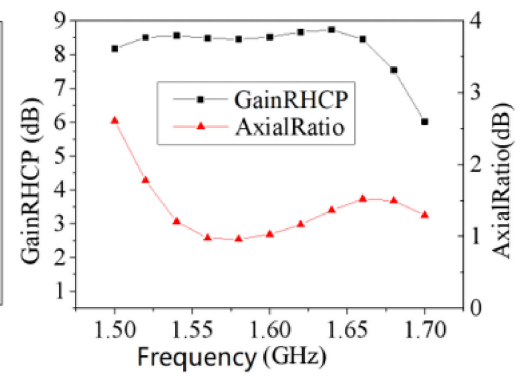

(b)

Fig. 3. Simulation results of antenna elements. (a) Return loss; (b) Normal point gain and axial ratio

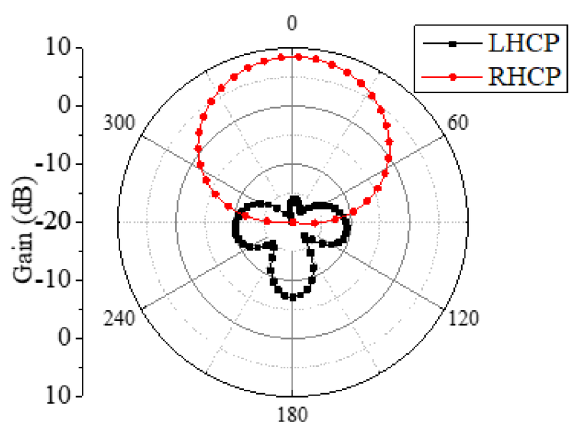

(a)

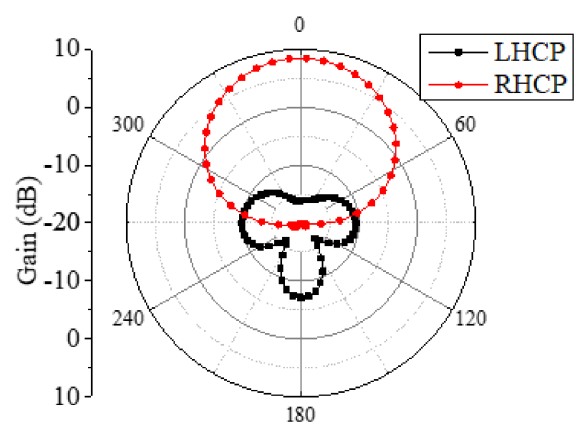

(b)

Fig. 4. Radiation pattern of antenna element at central frequency point. (a) Phi $=0^{\circ}$ plane; (b) $\mathrm{Phi}=90^{\circ}$ plane

\section{Design of sixteen element array}

The antenna uses a form of the pyramid cone. Fig. 6(a) is a schematic diagram of the placement of an array element. Fig. 6(b) is a schematic diagram of the array carrier. The array is in the form of 13 elements. 12 array elements are placed on six sides respectively. And 13th antenna element is placed on the upper surface. 


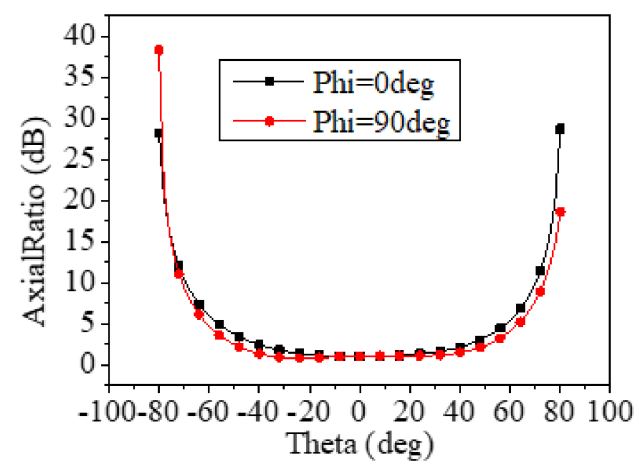

Fig. 5. Axial ratio at the center frequency point

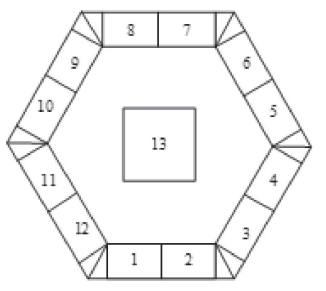

(a)

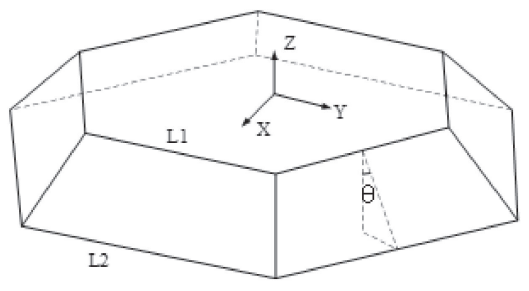

(b)

Fig. 6. (a) Schematic diagram of the placement of an array element; (b) Schematic diagram of the array carrier

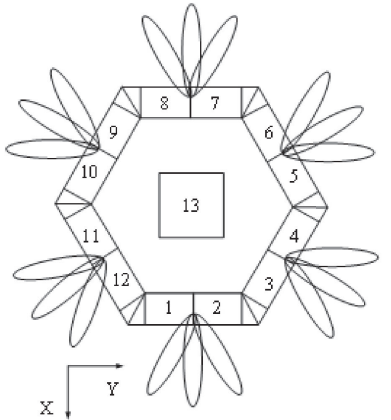

(a)

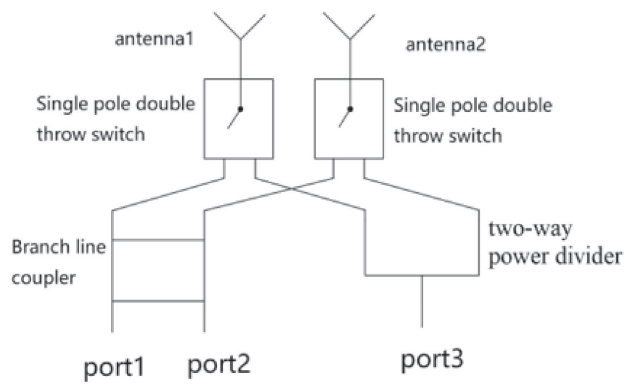

(b)

Fig. 7. The beam forming mechanism. (a) schematic diagram of beam coverage; (b) schematic diagram of side subarray beamforming.

Fig. 7 shows the beam switching mode adopted by the array. 12 antenna elements are located on six sides respectively. Two elements on each side form a subarray, each subarray forms 3 beams, covering a certain space area respectively. And the 6 subarrays of the side form 18 beams, each beam covering about 20 degrees along direction of $\varphi$.

For each subarray beam formation, as shown in Fig. 7(b), a single-pole doublethrow switch is connected to each subarray unit, followed by a $3 \mathrm{~dB}$ branch coupler and two-way power divider. According to the related principles described in the previous section, the two-output port has a stable phase difference of 90 degrees when the input port and the isolation port of the branch coupler respectively connection excitation (another port matched). When the port 1 is excited, the single-pole double-throw switch is hit to the left, the feed phase of the antenna 1 
will go ahead of the feed phase of the antenna 2, and the synthetic beam is offset to the direction of the antenna 2. This is the wave beam 1 . When the port 2 is excited, the single-pole double-throw switch will shift to the left side, and the synthetic beam is offset to the direction of the antenna 1 . And this is wave beam 2 . When port 3 is excited, the single-pole double-throw switch is directed to the right side, and the amplitude of the antenna 1 and the antenna 2 are equal, and the synthetic beam will radiate to the normal direction. This is the wave beam 3 .

The method of subarray scanning is used here. In order to make the wave beam distribution as uniform as possible, the scanning angle of the beam should be 20 degrees when the phase difference of the subarray element is 90 degrees. According to the formula $\beta d \sin \theta=\Delta$, the unit spacing is about $d=073 \lambda$. According to the center frequency point $1.6 \mathrm{GHz}$, the cell spacing is about $137 \mathrm{~mm}$. At this point, the circular polarized antenna unit in the first section of this chapter does not apply to this array structure, which is due to the large size of the antenna element, and the antenna element needs to be redesigned.

The stacked microstrip antenna is used in the third chapter. But in order to improve the circular polarization of element, we use this element to form an array. The model is shown in Fig. 8. We firstly observe the radiation pattern and the size of the gain of the element 13 which in the zenith position, because the size of the floor is much larger than the element design, and it will have a greater impact on its pattern. Fig. 9 is the main plane pattern of the center frequency point when the zenith unit is excited separately in the array environment. The phenomenon of beam broadening appears in the antenna pattern. The maximum gain is about $8.6 \mathrm{~dB}$, and the gain is greater than $8 \mathrm{~dB}$ when $\theta$ in the angle between positive and negative 24 degrees.

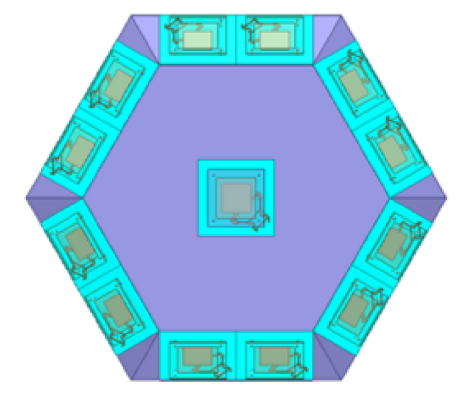

Fig. 8. Schematic diagram of the array model

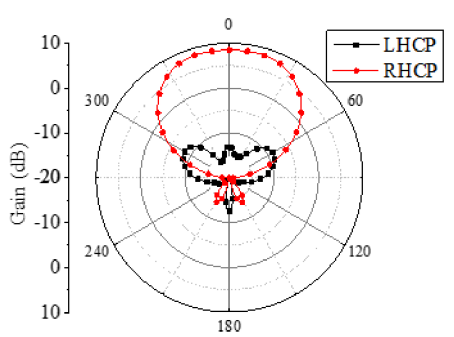

(a)

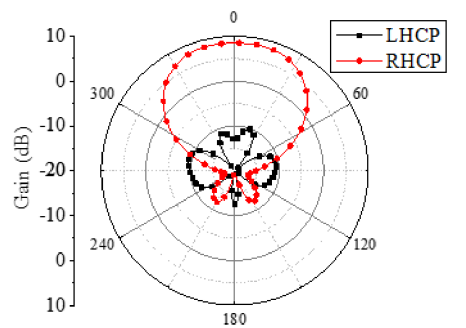

(b) 
According to the simulation results, the zenith maximum gain is basically unchanged. In order to achieve better coverage effect, the antenna element 13 in the zenith position is replaced by a subarray to increase the aperture efficiency of zenith region. The $2 \times 2$ circular polarization planar array designed in the third chapter of this paper, with high gain and good circular polarization, can be used directly. So, a sixteen-antenna array is formed, and the model diagram is shown in Fig. 10. At this point, the pattern of the zenith array at central frequency point is shown in Fig. 11. The antenna is a normal radiation, the maximum gain is $11.96 \mathrm{~dB}$, and the gain is greater than $8 \mathrm{~dB}$ when Theta between positive and negative 24 degrees, which is equal to the single element coverage, but the overall gain is higher.

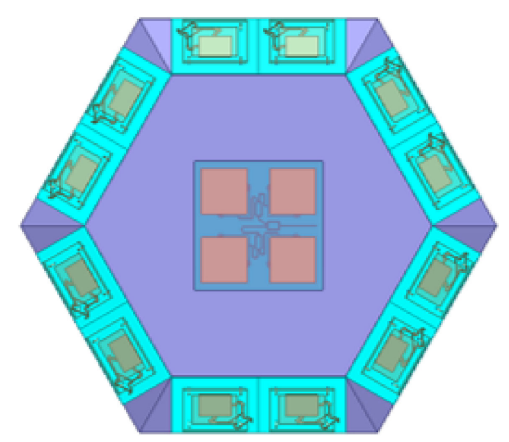

Fig. 10. Model schematic diagram

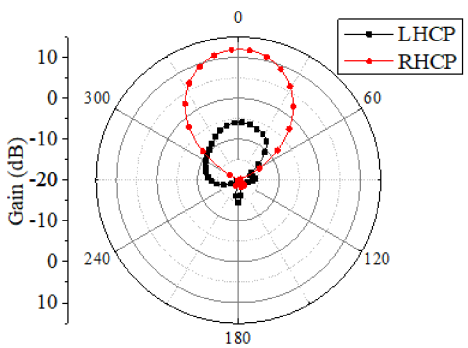

(a)

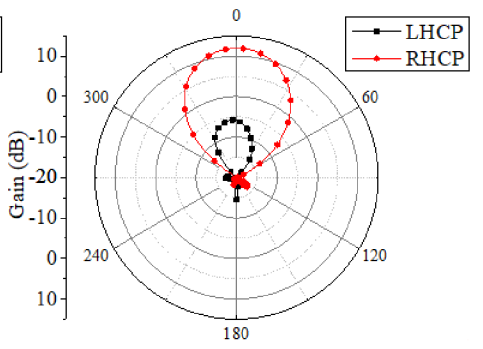

(b)

Fig. 11. The direction of the antenna top area at the center frequency point. (a) $\mathrm{Phi}=0^{\circ}$; (b) $\mathrm{Phi}=90^{\circ}$

Fig. 12 shows the active standing waves of the 1 and 2 antennas corresponding to the three beams of the subarray. In the three working conditions, the echo loss $-10 \mathrm{~dB}$ bandwidth can cover the $1.525 \mathrm{GHz} \sim 1.660 \mathrm{GHz}$ frequency band. The feed

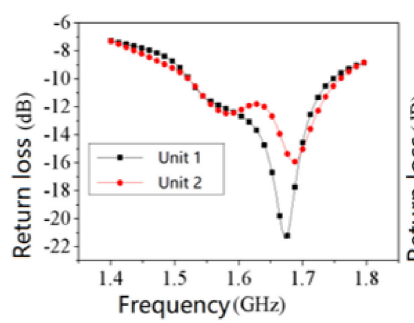

(a)

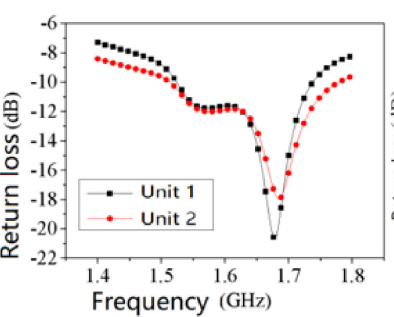

(b)

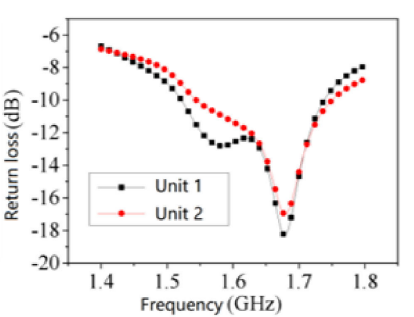

(c)

Fig. 12. Simulation results of active standing wave. (a) beam 1; (b) beam 2; (c) beam 3 
phase of the beam 1 is: $90^{\circ}$ for the 1 antenna, $0^{\circ}$ for the 2 antenna; the feed phase of the beam 2 is: $0^{\circ}$ for the 1 antenna, $0^{\circ}$ for the 2 antenna; the feed phase of the beam 1 is: $0^{\circ}$ for the 1 antenna, $90^{\circ}$ for the 2 antenna.

Table I give each beam sequence number, corresponding antenna unit and feed phase. Table II gives the maximum pointing position and maximum gain of each beam. As can be seen from Table I and Table II, each beam has a uniform direction, and the angle difference between the 18 beams of the lower element is about 20 degrees in the $\varphi$ direction, which is in agreement with the expectation.

Table I. The description of beam serial number

\begin{tabular}{|c|c|c|c|c|c|c|c|}
\hline $\begin{array}{c}\text { Beam } \\
\text { number }\end{array}$ & $\begin{array}{c}\text { Unit } \\
\text { number } \\
\text { and } \\
\text { phase }\end{array}$ & $\begin{array}{c}\text { Beam } \\
\text { number }\end{array}$ & $\begin{array}{c}\text { Unit } \\
\text { number } \\
\text { and } \\
\text { phase }\end{array}$ & $\begin{array}{c}\text { Beam } \\
\text { number }\end{array}$ & $\begin{array}{c}\text { Unit } \\
\text { number } \\
\text { and } \\
\text { phase }\end{array}$ & $\begin{array}{c}\text { Beam } \\
\text { number }\end{array}$ & $\begin{array}{c}\text { Unit } \\
\text { number } \\
\text { and } \\
\text { phase }\end{array}$ \\
\hline 1 & $\begin{array}{c}1: 0^{\circ} \\
2: 90^{\circ}\end{array}$ & 6 & $\begin{array}{c}3: 90^{\circ} \\
4: 0^{\circ}\end{array}$ & 11 & $\begin{array}{l}7: 0^{\circ} \\
8: 0^{\circ}\end{array}$ & 16 & $\begin{array}{c}11: 0^{\circ} \\
12: 90^{\circ}\end{array}$ \\
\hline 2 & $\begin{array}{l}1: 0^{\circ} \\
2: 0^{\circ}\end{array}$ & 7 & $\begin{array}{c}5: 0^{\circ} \\
6: 90^{\circ}\end{array}$ & 12 & $\begin{array}{l}7: 90^{\circ} \\
8: 0^{\circ}\end{array}$ & 17 & $\begin{array}{l}11: 0^{\circ} \\
12: 0^{\circ}\end{array}$ \\
\hline 3 & $\begin{array}{c}1: 90^{\circ} \\
2: 0^{\circ}\end{array}$ & 8 & $\begin{array}{l}5: 0^{\circ} \\
6: 0^{\circ}\end{array}$ & 13 & $\begin{array}{c}9: 0^{\circ} \\
10: 90^{\circ}\end{array}$ & 18 & $\begin{array}{c}11: 90^{\circ} \\
12: 0^{\circ}\end{array}$ \\
\hline 4 & $\begin{array}{c}3: 0^{\circ} \\
4: 90^{\circ}\end{array}$ & 9 & $\begin{array}{c}5: 90^{\circ} \\
6: 0^{\circ}\end{array}$ & 14 & $\begin{array}{c}9: 0^{\circ} \\
10: 0^{\circ}\end{array}$ & 19 & $\begin{array}{c}13: 0^{\circ} \\
14: 90^{\circ}\end{array}$ \\
\hline 5 & $\begin{array}{l}3: 0^{\circ} \\
4: 0^{\circ}\end{array}$ & 10 & $\begin{array}{c}7: 0^{\circ} \\
8: 90^{\circ}\end{array}$ & 15 & $\begin{array}{l}9: 90^{\circ} \\
10: 0^{\circ}\end{array}$ & & \\
\hline
\end{tabular}

The ultimate side tilt angle of the optimized carrier is $40^{\circ}$, and the overall size of the array is $770 \mathrm{~mm}(\mathrm{X}$ axis $) * 740.4 \mathrm{~mm}(\mathrm{Y}$ axis $) * 115.7 \mathrm{~mm}(\mathrm{H})$. The electric size is about $4.11 \lambda_{0} \times 3.95 \lambda_{0} \times 0.617 \lambda_{0}$, which $\lambda_{0}$ is the wavelength in the free space at the center frequency. Fig. 13 to Fig. 16 is the ultimate coverage of the antenna. The antenna can eventually achieve the gain coverage of $8 \mathrm{~dB}$ in the range of Theta $0^{\circ} \sim 70^{\circ}$, and the maximum axis ratio in the space area is $4.9 \mathrm{~dB}$, meeting the design requirements.

Table II. Maximum gain and direction of each beam

\begin{tabular}{|c|c|c|c|c|c|c|c|}
\hline Beam number & 1 & 2 & 3 & 4 & 5 & 6 & 7 \\
\hline Phi (deg) & 341 & 0 & 19 & 41 & 60 & 80 & 101 \\
\hline Theta (deg) & 51 & 49 & 51 & 51 & 48 & 50 & 51 \\
\hline GainRHCP (dB) & 10.45 & 10.95 & 10.52 & 10.64 & 11.09 & 10.69 & 10.65 \\
\hline Beam number & 8 & 9 & 10 & 11 & 12 & 13 & 14 \\
\hline Phi (deg) & 120 & 139 & 161 & 180 & 199 & 221 & 240 \\
\hline Theta (deg) & 48 & 49 & 51 & 49 & 50 & 51 & 48 \\
\hline GainRHCP (dB) & 11.08 & 10.64 & 10.42 & 10.94 & 10.55 & 10.67 & 11.08 \\
\hline Beam number & 15 & 16 & 17 & 18 & 19 & & \\
\hline Phi (deg) & 260 & 281 & 300 & 319 & 13 & & \\
\hline Theta (deg) & 50 & 51 & 48 & 49 & 1 & & \\
\hline GainRHCP (dB) & 10.66 & 10.62 & 11.06 & 10.60 & 11.97 & & \\
\hline
\end{tabular}




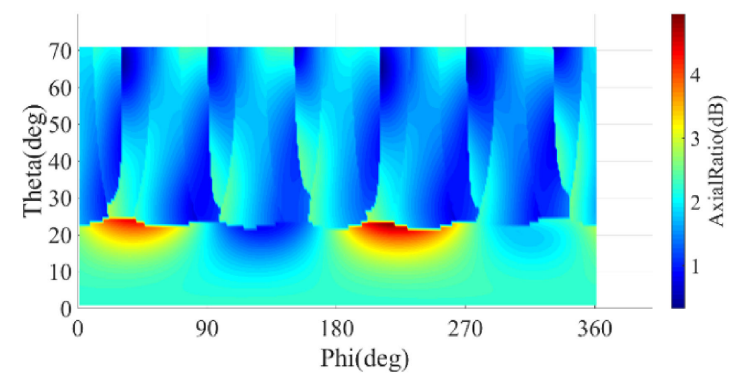

Fig. 13. Schematic diagram of the effect of space coverage

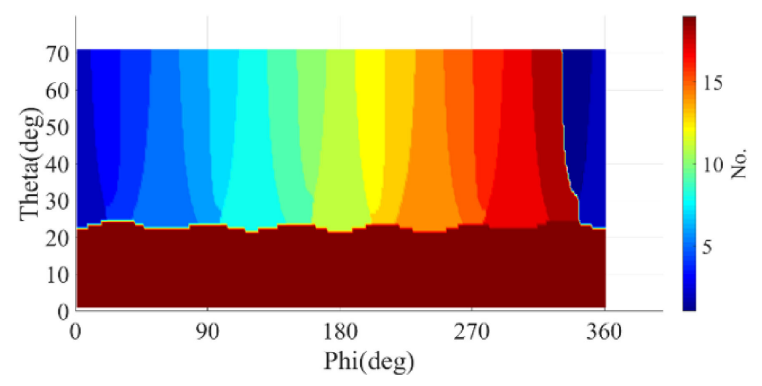

Fig. 14. The sequence number of a covering beam corresponding to a space point

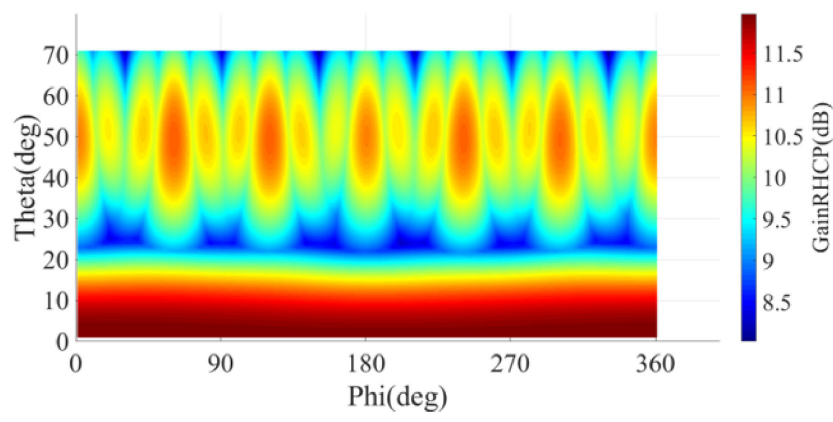

Fig. 15. Axis ratio of each point in space

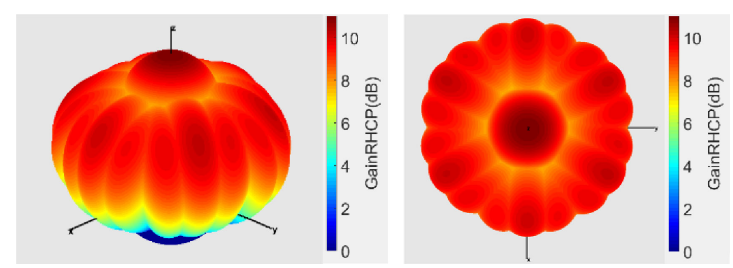

Fig. 16. 3D beam schematic diagram

\section{Results of antenna testing}

The array physical map of the sixteen-element array antenna is shown in Fig. 17(a). The test is carried out in the NSI darkroom, and the test site is shown in Fig. 17(b).

Fig. 18(a) shows the return loss test result of the lower unit. The return loss in the whole working band is less than $-10 \mathrm{~dB}$, which is in good agreement with the simulation. Fig. 18(b) and Fig. 18(c) are the test results of center frequency map and the axial ratio test results at the $1.6 \mathrm{GHz}$. Because the NSI system can only test 


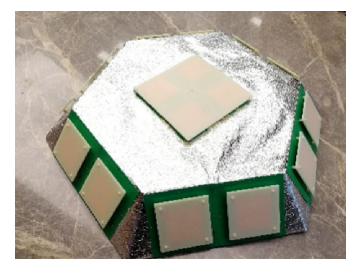

(a)

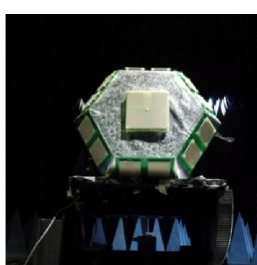

(b)

Fig. 17. (a) Physical antenna; (b) Test site

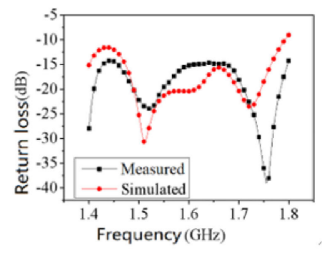

(a)

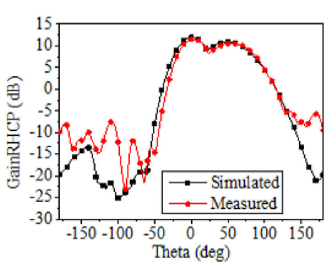

(b)

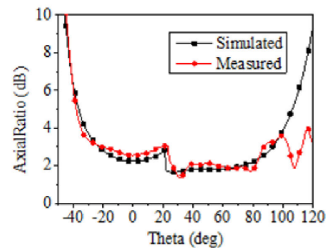

(c)

Fig. 18. (a) Test result of return loss in lower layer unit; (b) Test result of the gain direction diagram; (c) Test results of axial ratio

one surface field data, we only give the gain direction diagram and the axial ratio test results when $\varphi=0^{\circ}$. The test and simulation are basically consistent.

\section{Conclusion}

Based on the design of a laminated microstrip antenna unit, a wide-band circular polarization satellite antenna is designed. The antenna operates in $1.4 \mathrm{GHz} \sim$ $1.78 \mathrm{GHz}$. The normal gain in the frequency band is higher than $8 \mathrm{~dB}$, the axis ratio is less than $3 \mathrm{~dB}$, and the center frequency $3 \mathrm{~dB}$ beam width is 65 degrees. On this basis, a sixteen element form of Pyramid cone antenna array is designed. We can switch the beam by controlling the switch for each element. the switch of each element. The right circular polarization gain coverage of the azimuth $0^{\circ} \sim 360^{\circ}$ and the pitch angle of $0^{\circ} \sim 70^{\circ}$ is less than $8 \mathrm{~dB}$, and the circular polarization axis ratio in the whole angle domain is less than $3 \mathrm{~dB}$. Finally, the sixteen-element array is processed and tested, and the test and simulation are basically consistent. 